\title{
Inducing word-of-mouth by eliciting surprise - a pilot investigation
}

\author{
Christian Derbaix, ${ }^{1,2}$ \\ Facultés Universitaires Catholiques de Mons, \\ Laboratoire d'Analyse du Comportement du Consommateur (LABACC) \\ Joëlle Vanhamme, ${ }^{3}$ \\ Université Catholique de Louvain, \\ Fonds National de la Recherche Scientifique, \\ LABACC
}

\footnotetext{
${ }^{1}$ Authors are listed alphabetically. They contributed equally.

${ }^{2}$ Address: FUCAM, 151, Chaussée de Binche, 7000 Mons, Belgium. E-mail: derbaix@fucam.ac.be. Fax: +32 65323426

${ }^{3}$ Address: Unité MARK, Institut d'Administration et de Gestion, Université Catholique de Louvain, 1 Place des Doyens, 1348 Louvain-la-Neuve, Belgium. E-mail vanhamme@mark.ucl.ac.be. Telephone + 32-10 478478. Fax $+32-10478324$.
} 


\begin{abstract}
This research - using the critical incident technique - brings to the fore the emotion of surprise and its (direct and indirect) influence on word-of-mouth (WOM). The results show as expected - that the frequency and amount of WOM are larger for negatively and positively surprising consumption/purchase experiences than for non surprising experiences of the same kind and that the intensity of surprise is significantly correlated with positive and negative WOM.
\end{abstract}

Keywords: word-of-mouth, surprise, emotions, social sharing, critical incident technique. 


\section{Introduction}

Word-of-mouth (WOM) is the most important informal means of communication between consumers (Filser, 1996). It is defined as "the informal communication directed at other consumers about ownership, or characteristics of particular goods and services and/or their sellers" (Westbrook, 1987). The reasons justifying the power of WOM are first that WOM is more credible than commercial sources of information controlled by companies (e.g. advertising, sponsorship). Most of our discussions are indeed with friends, family, i.e. people we trust and whose goal is not the promotion of a specific company. Second, WOM is really communication, i.e. the message flow tends to be two-way. Third, WOM provides potential consumers with a description of what the experience would be and is thus considered to be a risk reliever, especially for experience goods (Filser, 1996; Wilkie, 1990). WOM can be either positive or negative (Buttle, 1997). According to Buttle (1997, p. 4), "positive WOM occurs when good news testimonials and endorsements desired by the company are uttered" and "negative WOM is the mirror image".

In a seminal study, dealing with the two-step flow theory, Katz and Lazarsfeld (1964) stressed that WOM by opinion leaders can accelerate the diffusion of innovations, information, etc. Similarly, Arndt (1967a) suggested that WOM could be used to supplement the mass-media. Furthermore, he reported that exposure to favorable WOM increased the probability to purchase the product and, conversely, that exposure to negative WOM decreased that probability (Arndt, 1967b). Webster (1988; 1991 referenced by Buttle, 1997) also showed that, for some services, WOM is an important factor in consumer's information search, evaluation and buying processes. Moreover, Reichheld and Sasser (1990) reported that positive WOM, not only, reduces the need for marketing expenditures but might also increase revenue if new customers are attracted. In contrast, negative WOM has been shown to reduce 
the credibility of a company's advertising (Solomon, 1998). Thus, WOM is really a two-edged sword: whereas eliciting positive WOM is a way of gaining success through an image building effect, negative WOM is damaging for the company due to an image killing effect (even more so because negative WOM is weighted more heavily by consumers than positive comments (Solomon, 1998)).

The question is thus 'how to encourage positive WOM?'. In this article, we argue that positive surprise is a privileged means to initiate positive WOM and that the polarity of surprise should be carefully controlled since negative surprise is likely to trigger off important negative WOM. In the following sections, we first describe the emotion of surprise and outline its causes and consequences. Then we examine the WOM phenomenon and delineate its hypothetical links with surprise. Finally the methodology and the results of the pilot study are described.

\section{Surprise: definition, causes and consequences.}

What is known about surprise originates mainly from the literature in psychology. So far, only a few attempts have been made to provide a conceptual framework and specifically investigate this particular emotion in a marketing context (e.g., Derbaix and Vanhamme, 2000; Vanhamme, 2000; Vanhamme and Lindgreen, 2001). This apparent disregard for surprise is ... surprising since some researchers urged to study it (e.g., Derbaix and Pham, 1991; Westbrook and Oliver, 1991) while some others complained about the lack of a theoretical framework in the consumer behaviour literature for investigating it (Oliver et al., 1997). Moreover, surprise might be useful in a variety of domains. For example, it has been 
argued that surprise is a privileged way to capture consumers' attention in our era of advertisement overcrowding (Derbaix and Pham, 1991).

There has been a lack of consensus, in psychology, on what is an emotion and, as a result, also about the status of surprise. A few researchers such as Ortony et al. (1988) consider that surprise is not an emotion because it is not valenced whereas, according to these authors, emotions should have a valence - i.e. be either positive or negative. In contrast, numerous researchers (e.g. Bain, 1874; Charlesworth, 1969; Desai, 1939; Ekman and Friesen 1975, 1985; Izard, 1977, 1991; Izard and Buechler, 1980; Plutchik, 1980; Ribot, 1911; Ruckmick, 1921; Warren, 1920; Woodworth et Schlosberg, 1954) and the bulk of recent studies carried out in psychology on surprise (e.g. Meyer and Niepel, 1994; Meyer et al., 1997; Niepel et al., 1994; Reisenzein, 2000; Reisenzein et al., 1996; Schützwohl, 1998) consider it an emotion. Like Derbaix and Pham (1991), the present study adopts thus the point of view that surprise is an emotion.

Surprise is a neutral (i.e. not valenced) and short-lived emotion elicited by a "schema

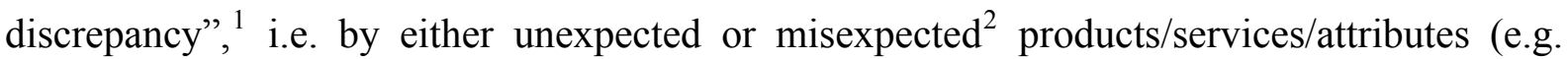
Ekman and Friesen, 1975; Meyer et al., 1994, 1997; Scherer, 1984; Schützwohl, 1998). A

\footnotetext{
${ }^{1}$ Another theoretical causal framework for surprise - the attributional model (Weiner 1985) - has also been suggested in the literature. According to this model, unexpected events do not elicit surprise but elicit causal search and attributions. If attributions are attributions to chance, then surprise is elicited but not otherwise. This model has, however, been strongly criticised by Stiensmeier-Pelster et al. (1995) who pointed out several theoretical problems related to it and provided some empirical evidence that did not support the model. Evidence against the attributional model can also be found in Gendolla (1997).

${ }^{2}$ The former denotes vague and not well-defined expectations about the products/services/attributes. The latter denotes precise expectations about the products/services/attributes that do not occur.
} 
schema is a type of private, usually informal, inarticulate, unreflective theory about the nature of objects, events or situations (Rumelhart, 1984). In order to have a proper representation of the reality, individuals continuously check whether their schema matches the inputs coming from the surrounding environment. This check is, however, relatively unconscious (Scherer, 1984). As soon as inputs diverge from the schema, surprise is elicited.

It should be emphasised that surprise should not be equated with the awareness of a schema discrepancy (Stiensmeier-Pelster et al., 1995). Surprise is an emotion that is defined by a syndrome of reactions (see Fig. 1), i.e. a specific pattern of reactions at the subjective (e.g. subjective feeling), physiological (e.g. increase in the skin conductance, changes in heart and respiration rates) and behavioural levels (e.g. Meyer et al., 1997; Reisenzein, 2000; Reisenzein et al., 1996; Schützwohl, 1998). At the behavioural level, surprise is characterised by a specific facial expression (i.e. opened eyes and mouth, raised eyebrows). In 1872, Darwin suggested that the purpose of the eye widening and eyebrows raising (which increases the field of vision) was to help the visual investigation (and understanding) of the surprising event (see also Goleman (1997, p. 7)). In addition to this non-social explanation of the surprise display, Reisenzein et al. (1996) suggest that the facial expression of surprise might also help the surprised individual to analyse the event by communicating to others his/her emotional and mental state and, in this way, solicit their help. Another major behavioural characteristic of surprise - besides its facial expression - is the interruption of ongoing activities (e.g. Meyer et al., 1991). Tomkins (1962), for example, describes surprise as a "general interrupter to ongoing activities" and contends that "this mechanism is similar in design and function to that of a radio or television network which enables special announcements to interrupt any ongoing program" (Tomkins, 1962, p.498). An argument of the same kind is provided by Izard (1991) who considers that the function of surprise is to 
clear out our nervous system of ongoing activities that would interfere with adjustment to a schema discrepancy in our environment. A spontaneous focusing of attention on the schema discrepant event follows the interruption of activities and results in a heightened consciousness of the surprising stimulus at the expense of other stimuli (the potential of interference of those stimuli is therefore limited) (Charlesworth, 1969; Niepel et al., 1994). The interruption of ongoing activities, the focusing of attention and the heightened consciousness of the surprising stimulus are supposed to help the individual to process the surprising event (Schützwohl, 1998). Linked to the focusing of attention, surprise also results in a better retention in memory of the surprising stimulus (e.g. Meyer et al., 1997). Eventually, surprise also gives rise to an exploration / curiosity behaviour (which may also be coupled - at the subjective level - with "why?" questions) (Charlesworth, 1969). Figure 1 gives an overview of the components of the emotion of surprise at each level.

All instances of surprise involve reactions at these three levels. However, they can differ in their specific manifestations. At the behavioural level, for example, opened eyes and raised eyebrows may not appear if there is no need for a visual search for more information (Reisenzein and Bördgen, 1998).

INSERT FIG. 1 ABOUT HERE

As a result of the evaluation of the pleasantness / unpleasantness of the experience - which is subsequent to the evaluation of the schema discrepancy (Scherer, 1984) - the emotion of surprise is often followed by another emotion that colours it either positively (e.g. surprise + joy) or negatively (e.g. surprise + anger) (Ekman and Friesen, 1975, Meyer et al., 1994). This explains why people talk about good or pleasant surprise and bad or unpleasant surprise. 
It is also worth noting that the emotion of surprise, via its intrinsic arousal, can amplify subsequent affective reactions (Charlesworth, 1969; Desai, 1939). Thus, someone who has just been surprised by an unexpected/misexpected pleasant [unpleasant] event will experience more joy [anger], for example, than someone in a similar situation who has not been surprised previously. This characteristic of surprise can be explained by the theory of excitation transfer, in which residues of activation from prior stimulation combine with excitation in subsequent stimulation. The combined activity is then expected to intensify the emotional experience during the subsequent stimulation (e.g. Zillmann, 1983).

Finally, surprise results in processes that aim at eliminating the schema discrepancy, i.e. a causal search and causal attribution (Stiensmeier-Pelster et al., 1995) and, if necessary, the updating of the relevant schema (e.g. Meyer et al., 1994). If the schema is updated, the same stimulus is not likely to elicit surprise once again since it becomes part of the schema and, thus, is expected.

\section{WOM: social sharing of emotions revisited}

Several determinants of the positive and negative WOM activity have been researched (see Buttle, 1997 for a comprehensive review). With respect to positive WOM, it has, for example, been empirically established that satisfied customers are more prone to engage in positive WOM (e.g. Söderlund, 1998; Swan and Oliver, 1989). The old proverb "the satisfied customer is your best salesman" is still well alive! Moreover, Hartline and Jones (1996) reported that intention to engage in positive WOM is positively correlated with customer perceptions of value and quality. Positive WOM is also triggered by feelings of equity (i.e. "fair deal", Swan and Oliver, 1989), product/service performances (Tanner, 1996 referenced 
by Buttle, 1997) and by the perceived social support displayed by the service provider (i.e. verbal and non-verbal communication toward the customer) (Adelman and Ahuvia, 1995).

Antecedents of negative WOM - which is considered to be one of the forms of customer complaining behavior (Singh, 1988) - have also been investigated. Söderlund (1998), for example, found a fairly symmetrical relationship between satisfaction and WOM (i.e. U shaped curve); just as favourable satisfaction triggers off positive WOM, dissatisfaction leads to negative WOM. High price, difficulty of repair, consumer's external attributions of blame (in case of product failure) and consumer's negative perceptions of the retailer responsiveness to complaints were also shown to be positively related to negative WOM (Richins, 1983).

Eventually, specific contexts, such as repetitive advertising (Bayus, 1985; Tax and Chandrashekaran, 1992; Tax et al., 1993) or unusual advertising (King and Tinkham, 1990) are known to generate more WOM.

The influence of emotions on WOM has, however, not been systematically investigated, with the exception of the field study by Westbrook (1987). This author reported that salient positive and negative emotions stimulated WOM communication. In addition, he showed that the influence of positive and negative emotions was unmediated by satisfaction and by satisfaction's cognitive antecedents (i.e., expectation and disconfirmation beliefs). In the same vein, Maute and Dubé (1999) - using a mental simulation of a core service failure - showed that emotional responses accounted for a large part (about 30\%) of the explained variance of WOM intentions. This link between emotions and WOM can be related to the phenomenon of "social sharing of emotions", thoroughly researched by Rimé and colleagues -among othersin psychology. Social sharing is defined as "a phenomenon involving 1) the evocation of the 
emotion in a socially shared language and 2) at least at the symbolic level at some addressee" (Rimé et al., 1992, p. 228). It has been shown that people experiencing everyday life emotions initiate communication processes during which they share parts of their private experience with social partners (friends, parents, etc.). Only about 10\% of emotional experiences are kept secret (Rimé et al., 1991a; Rimé et al., 1991b; Rimé et al., 1992), i.e. are never socially shared. Furthermore, it seems that there are no differences according to the type of emotional life event (Rimé et al., 1995). It has also been reported that the frequency of social sharing is a positive function of the disruptiveness of the event: the more disruptive an event (i.e. it challenges some basic beliefs), the sooner and the more frequently it is shared (Rimé et al., 1992). Social sharing of emotions is also positively related to the intensity of the felt emotion (Rimé et al., 1998). Note, however, that the review by Rimé et al. (1998) concluded that the relation between intensity and extent of social sharing is not linear but more like a step function. Interestingly social sharing does not extinct after the first social sharing; people who listen to social sharing of emotions initiate secondary social sharing. The more intense the emotional event, the more people engage in secondary social sharing (Christophe and Rimé, 1997). Thus, there is a possibility of snowball interpersonal communication, i.e. to elicit a "you know what I have been told?" reaction.

\section{How does surprise relate to WOM?}

Studies carried out on social sharing of emotions have analysed emotional life events. Usually emotions experienced in consumption/purchase contexts are likely to be milder than everyday life emotions. As mentioned by Richins (1997, p. 129), "emotions that arise in the context of an intimate interpersonal relationship are likely to differ in intensity and quality from the emotions experienced when buying a pair of shoes". One might easily admit that even though 
the shoes are just nice (i.e. they match the consumer's schema), the emotional experience (if any) could hardly be qualified as "disruptive" or "intense" and therefore will probably not initiate any social sharing, i.e. WOM. However, if the consumer experiences surprise, the situation might be different. For example, imagine that the shoes are really wonderful leather shoes for only the price of 50\$ (in Spain)!

As mentioned above surprise is characterised by a spectrum of changes such as interruption of ongoing activities, focus of attention, physiological changes, etc., which are "disruptive". Additionally, surprise elicits substantial cognitive work (causal search, causal attribution, schema updating, and so on) and as mentioned by Söderlund (1998), this cognitive burden could lead to more interactions with others to the extent that interactions with others can help the individual in alleviating this burden. Therefore, the likelihood of inducing social sharing (WOM) is high. According to what precedes, there should be a direct link between surprise and WOM. A surprised consumer should engage in more WOM than a non-surprised consumer, and the more surprised the consumer is, the more he/she should initiate WOM. This leads to the following hypotheses:

H1: The frequency of WOM (i.e. how many times the consumer talks about his/her experience to someone else) should be higher for a surprising experience than for a non-surprising experience.

H2: The frequency of WOM should be positively related to the intensity of surprise experienced during the purchase/consumption. 
Furthermore, surprise is often immediately followed by other positive or negative affective reactions resulting from the evaluation of the (un)pleasantness of the consumption/purchase experience (Scherer, 1984). Due to the amplification property of surprise, the intensity of these affective reactions will be higher than if they had not been preceded by surprise. Therefore, surprise might also indirectly influence the frequency of WOM through these subsequent affective reactions. From a managerial point of view, what is relevant to study is what is commonly referred to as "pleasant (or positive) surprise" but this blend does not conceptually exist. However, to reconcile practice and theory, it is possible to investigate surprise with the subsequent emotions that colour it. Hence, the following hypothesis can be tested:

H3: Surprise also positively influences the frequency of WOM indirectly through subsequent affective reactions.

Finally, surprise is an emotion whose characteristics (i.e. interruption of ongoing activities, focusing of attention on the surprising stimulus and heightened consciousness of the surprising stimulus, increased visual field due to the facial display of surprise; see Fig. 1, behavioural level) allow surprised consumers to take in and memorise as much information as possible about the surprising event (e.g. Meyer et al., 1997). Therefore, consumers experiencing surprise during their product or service purchase/consumption are likely to memorise and, subsequently, to be able to share with other people a larger number of different elements about their experience than non surprised consumers. This leads to the following hypothesis: 
H4: The amount of different elements shared with other people should be larger for a surprising experience than for a non-surprising experience.

\section{Methodology}

\subsection{Critical Incident Technique}

The method chosen for this pilot study is the Critical Incident Technique (CIT). This method is well-suited to our research. Its purpose is to thoroughly describe and understand a realworld phenomenon about which little is known (Bitner et al, 1990). The CIT, which is rooted in psychology, has been clearly explained by Flanagan (1954). It consists of a set of procedures for collecting and classifying (through content analysis) observations of human behaviour - having special significance and meeting systematically defined criteria- in such a way as to make them useful in addressing practical problems. In summary, it is essentially a procedure for gathering important facts concerning behaviour in defined situations (Flanagan, 1954). This method has been used in several marketing studies, for instance, in satisfaction studies and in service encounters studies (e.g. Swan and Combs, 1976; Folkes, 1984; Hausknecht, 1988; Bitner et al., 1990; Johnston, 1995). It has also been used in studies on social sharing (see Rimé et al. 1998). Critical incidents are defined as extreme incidents (e.g. particularly involving or salient purchase experiences, particularly satisfying or dissatisfying consumption experiences). As such it is an advantage of the technique since "extreme" incidents can be more accurately recalled than those which are more mundane (Flanagan, 1954). ${ }^{3}$ Another advantage of the method is that it allows consumers to express their

\footnotetext{
${ }^{3}$ Surprising experiences may indeed be considered as "outstanding, extreme" situations since they are not likely to be frequent among all consumption/buying experiences.
} 
perceptions in their own words. For the purpose of this study, critical incidents are defined as positively or negatively surprising consumption/buying experiences. The use of CIT will thus here provide a deep understanding into what consumers classify as "positively and negatively surprising experiences". The CIT has however some disadvantages related to the problems of retrospection and introspection. This first problem is nonetheless limited when reported incidents are recent and "observers" (i.e. consumers) are motivated to engage in detailed observations/evaluations during the occurrence of the incident. This last condition is fairly matched in the case of surprising experiences since the emotion of surprise is known to lead to an analysis of the event. Nonetheless, due to the object of our study - i.e. emotions - some respondents might not be willing to reveal some aspects of their private emotional consumption/purchase experiences. Therefore, some forms of demand artefact and/or selective memory could take place.

\subsection{Data collection}

Half of the participants, i.e. 50 respondents, were instructed in a questionnaire to remember and explain into details a consumption/purchase experience (product/service) which surprised them positively and for the purpose of comparisons, their last experience with the same kind of product/service which did not surprise them. The other half of the participants (i.e. 50 respondents) was assigned the same task but for negatively surprising experiences. Thus, the total sample includes 200 observations provided by 100 respondents.

Using the Izard's five points DES scale (Izard, 1977) for emotions, we collected verbal measures of surprise and other emotions (see appendix 2). Collecting verbatims similar to the ones reported by Richins (1983), Swan and Oliver (1989) and Oliver (1997) (i.e. frequency; 
number, nature and valence of reported elements) was our basis to assess WOM activity (see appendix 2).

Our respondents were drawn from within thirty to fifty-year-old consumers, i.e. consumers being likely to report surprising and non surprising experiences in a variety of domains. Special care was taken in order to recruit comparable respondents for positively and negatively surprising experiences (essentially consumers having experienced the same kind of products and services, living in the same urban areas, coming from middle or upper middle class and with the same types of leisure activities).

Prior to the final data collection, a pre-study was carried out with 24 (other) respondents from the target population in order to check the quality of the questionnaire. As a result, some questions were modified or clarified. The data of this pre-study - undertaken to gather additional information with respect to our literature review - also strengthened most of our convictions concerning the relevance of our hypotheses.

\section{Findings}

In a field study, there could be a number of differences between surprising and non surprising experiences aside from the elements eliciting surprise that threatens the comparability of the surprising versus the non surprising samples. However, in our CIT procedure, respondents were clearly requested - in the very first part of the questionnaire - to fully describe the context (i.e. surrounding, background, people involved, etc.) of the surprising as well as of the non-surprising consumption/purchase experience. A content analysis of the verbatims collected in these two questionnaires did not reveal any salient elements contrasting these two situations, most of our respondents reporting very few elements about the context in which 
their experience took place. It can be assumed that if something important with regard to the context had occurred, respondents would have mentioned it. Therefore, it seems reasonable to conclude that both samples are comparable apart from non reported and thus minor elements.

The surprising experiences involved products (e.g., food, electrical appliances, cosmetics, cars, clothing) in about $60 \%$ of the cases and services (e.g., restaurants/bars, movies, information services, theatre) in about $40 \%$ of the cases. The same kind of products/services were involved in both positively and negatively surprising experiences. The reported causes of positively and negatively surprising experiences were related to newness of the product, price/quality ratio, out of stock problems, failure or bad quality, factors linked to atmospherics and differences between what was ordered and what was delivered (see appendix 1 for selected vignettes).

Prior to testing the research propositions, usual checks of reliability were conducted. All multi-items variables used for testing our hypotheses had highly acceptable Cronbach alpha (above .8) (see appendix 2 for the items which were aggregated). Distributions were also checked for normality. Since the normality assumption did not hold for most of the distributions, non parametric statistics will be carried out to test the hypotheses. ${ }^{4}$ However, results for parametric statistics will also be provided as complementary information.

\footnotetext{
${ }^{4}$ Different non parametric tests were carried out (e.g. for correlations: Kendall T and Spearman Rho; for differences between two related groups: Wilcoxon signed ranks test and sign test; for differences between two independant samples: Mann-Whithney test and Kolmogorov-Smirnov test; see Siegel and Castellan (1988)). However, only one test will be reported each time since the different non parametric tests provided similar results. Unless specified $\left(\mathrm{p}_{1 \mathrm{~T}}\right)$, all tests are 2-tail.
} 
Results for H1. As expected, the frequency of positive WOM is higher for the positively surprising experiences than for the non surprising experiences (Wilcoxon signed ranks test $\mathrm{Z}$ $=-5.244, \mathrm{p}_{1 \mathrm{~T}}=0.000 ;$ Mean FWOM PoSE $=5.94$ vs. Mean FWOM NonSE $=0.92, \mathrm{t}(49)=6.96$, $\left.\mathrm{p}_{1 \mathrm{~T}}=0.000\right)$. Similarly, negative WOM appears to be more frequent for the negatively surprising experiences than for their non surprising counterparts (Wilcoxon signed ranks test $Z=-5.294, p_{1 \mathrm{~T}}=0.000 ;$ Mean FWOM ${ }_{\mathrm{NeSE}}=5.58$ vs. Mean $\mathrm{FWOM}_{\mathrm{NonSE}}=0.70, \mathrm{t}(49)=6.31$, $\mathrm{p}_{1 \mathrm{~T}}=0.000$ ). An analysis was also conducted on the difference that might exist with respect to the frequency of WOM between positively and negatively surprising experiences. No significant difference was found for the frequency of WOM between both kind of experiences (Mann-Whithney $Z=-0.9, p=0.464$; Mean FWOM PoSE $=5.94$ vs. Mean FWOM NeSE. $=5.58$, $\mathrm{t}(98)=0.317, \mathrm{p}=0.752)$.

Results for H2. On the basis of the fifty positively surprising experiences and the fifty negatively surprising experiences, the intensity of surprise does not seem to be significantly correlated with the frequency of WOM (H2). However, this might be explained by a possible non linear function - and more precisely, a step function (see supra) - between the intensity of surprise and WOM or by the rather low variance of the scores of surprise in the surprising samples (Scores of surprise for surprising experiences are relatively high and homogenous: Positively surprising experiences: Mean SUR $=4.2$, S.D SUR $=0.88$, percentile SUR $[10]=3$ // Negatively surprising experiences: Mean SUR $=4.6$, S.D. SUR $=0.53$, percentile SUR [10] = 3.7. The use of the CIT technique could partially be responsible for the problem of low variance).

In order to solve the problem of variance and step function, the same analysis was conducted on a new 'positive sample' $(\mathrm{N}=100)$ and a new 'negative sample' $(\mathrm{N}=100)$. The 'positive 
sample' is composed of the fifty answers related to the positively surprising experiences and the fifty answers given by the fifty other respondents while describing their non surprising experiences. In a similar way, the 'negative sample' is composed of the fifty answers related to the negatively surprising experiences and the fifty answers given by the other fifty respondents while describing their non surprising experiences. These two 'new samples' were so built in order to preserve independence between observations. Before building these two new samples, we checked for the comparability of both sets of 50 non surprising experiences (i.e. data that were recorded - for the two original samples of 50 respondents - in the part of the questionnaire devoted to the non surprising experience). ${ }^{5}$ The results - coming out of these two samples of one hundred observations - support H2: a highly significant positive correlation is found between surprise and WOM in the 'positive sample' and in the 'negative sample' (Positive sample: Kendall $\mathrm{T}=0.369$, Pearson $\mathrm{r}=.389, \mathrm{~N}=100, \mathrm{p}_{1 \mathrm{~T}}=0.000 / /$ Negative sample: Kendall $\mathrm{T}=0.447$, Pearson $\left.\mathrm{r}=.463, \mathrm{~N}=100, \mathrm{p}_{1 \mathrm{~T}}=0.000\right)$.

Results for H3. As for $\mathrm{H} 2$, the 'negative' $(\mathrm{N}=100)$ and 'positive' $(\mathrm{N}=100)$ samples were used in order to test H3. As can be seen on the first graph in figure 2 (positive sample), surprise is correlated with enjoyment (see appendix 2) and this subsequent affective reaction is correlated with the frequency of WOM. This indicates the existence of an indirect link between surprise and the frequency of WOM through subsequent emotions. Furthermore, as can be seen in cell 1 of figure 2 (positive sample), enjoyment does not fully mediate the influence of surprise on WOM: the Kendall rank-order correlation between surprise and WOM drops from 0.369 to 0.290 once controlled for enjoyment but remains significant (as announced, parametrical analyses - using the Baron and Kenny (1986) procedure - are reported as additional information; see cells 2-4). Similar results appear for the negative

\footnotetext{
${ }^{5}$ No significant difference was found on the variables related to the characteristics of the respondents (sex, age and personality (using Saucier (1994) mini-markers)), emotions (DES scale) and WOM (amount and frequency).
} 
sample (Fig. 2, graph b). Non parametrical analyses show significant correlations between surprise, negative emotions (see note 1, Fig. 2) and the frequency of WOM. Furthermore, negative emotions do not fully mediate the influence of surprise on the frequency of WOM: the Kendall rank-order correlation between surprise and WOM drops from 0.447 to 0.120 once controlled for negative emotions but still remains significant (cell 5; Note: parametrical results are not convergent (see cell 8)).

INSERT FIG. 2 ABOUT HERE

Results for H4. In accordance with H4, a larger amount of elements shared is found for positively and negatively surprising experiences than for non surprising experiences (Positively surprising experiences: Wilcoxon signed ranks test $Z=-4.852, \mathrm{p}_{1 \mathrm{~T}}=0.000$; Mean $\mathrm{AWOM}_{\mathrm{PoSE}}=2.4$ vs. Mean AWOM $\mathrm{NonSE}=0.3, \mathrm{t}(49)=6.314, \mathrm{p}_{1 \mathrm{~T}}=0.000 / /$ Negatively surprising experiences: Wilcoxon signed ranks test $Z=-4.883, \mathrm{p}_{1 \mathrm{~T}}=0.000$; Mean AWOM $\mathrm{NeSE}$ $=1.7$ vs. Mean $\left.A W O M M_{\text {NonSE. }}=0.4, t(49)=6.464, p_{1 \mathrm{~T}}=0.000\right)$. An additional analysis of the potential difference in amount of element shared between positively and negatively surprising experiences did not reveal significant difference (Mann-Whithney $Z=-1.437, p=0.076$; Mean $\mathrm{AWOM}_{\mathrm{PoSE}}=2.4$ vs. Mean $\mathrm{AWOM}_{\mathrm{NeSE}}=1.7$, variances not equal $\mathrm{t}(80.904)=1.835$, $\mathrm{p}=0.07)$

\section{Discussion and conclusions}

The purpose of this research was to highlight the role of surprise in eliciting WOM. Our four hypotheses were supported by the data. The frequency and amount of WOM were clearly larger for negatively and positively surprising experiences than for their non surprising counterparts. Highly significant correlations were found between surprise, subsequent 
emotions and the frequency of WOM. Moreover, the correlations between surprise and WOM remained significant while controlling for subsequent emotions. Thus, although our results clearly bring the impact of subsequent emotions on WOM to light, they also show that these emotions do not fully mediate the influence of surprise on WOM. As a result, the basic/primary emotion of surprise deserves a thorough analysis per se.

Concerning subsequent emotions, it appears - especially from our principal component analysis of negative affective reactions - that what essentially matters is their valence. Clearly, all the items related to distress, anger, fear, disgust and contempt loaded very highly on the same component. This suggests that what retrospectively remains of subsequent emotions is not the specific content of each of them but only their valence, i.e. a global positive or negative affective tone that 'colours' surprise. In other words, retrospective descriptions of WOM do not seem to reflect shades of the various emotions experienced during the consumption/purchase but rather encompass elements linked to the causes and effects of the 'coloured' emotion of surprise (see vignettes in appendix 1). Consequently, it appears that the intensity of surprise and the valence of the subsequent emotions are two key determinants of WOM, at least when assessed retrospectively. With respect to this last element, let us stress that the kind of retrospection we are dealing with in our study seems very similar to the one expected when true WOM takes place. There is always a delay between the surprising experience and the WOM that might follow. Moreover, the longer the delay between the consumption/purchase experience and the WOM activity, the more likely the elements shared by the consumer about his/her surprising experience will just convey verbatims describing the intensity of surprise and the valence of the subsequent emotions. 
With respect to the differences between positively and negatively surprising experiences, neither the amount of different elements shared with other people nor the frequency of WOM did significantly differ. As far as the frequency of WOM is concerned, the results of the present study corroborates those of studies carried out by Rimé and colleagues in the literature on social sharing of emotions. This literature shows that the frequency of social sharing (i.e. WOM) for negative episodes does not differ significantly from social sharing for positive episodes (Rimé et al., 1991a; Rimé et al., 1992). It is, however, worth noting that contradictory empirical findings can be found in the marketing literature with respect to the relative impact of positive versus negative experiences on WOM. For example, Hart et al. (1990) found that negative experiences generate more WOM than positive experiences, while the results of Holmes and Lett (1977) led to the opposite conclusion. Theoretical arguments that support both results can also be found in the literature (i.e. a "negativity bias" versus a "positivity bias", see Söderlund (1998) for a review). These studies did, however, not specifically examine surprising negative or positive experiences and it should be kept in mind that the surprising nature of the experience is already likely to lead to a higher frequency of WOM. That might explain that the "possible" differential increase in frequency due to the valence of the experience is non-significant. With respect to the amount of elements shared, these results may seem at odds with "popular wisdom" and the literature. Several studies have shown that negative affective states lead people to narrow and focus their attention on the eliciting-stimulus to a greater extent than positive affective states do (Taylor, 1991). As a result, people experiencing negative affective states are able to take in and, subsequently, share more information on the negative stimulus than people experiencing positive affective states. However, the non significant difference found in our study might be explained by the surprising nature of the experience since surprise already leads to a greater focusing of attention on the stimulus. 
The findings of the study have implications for management practice and future research. All our results bring to the fore the indubitable influence of surprise on WOM: the more surprised the consumer, the higher the frequency of WOM. From a managerial point of view, it is thus worth thoroughly thinking about eliciting (positive) surprise - i.e. giving a kind of unique experience to the consumers - because these surprised consumers will probably advertise their experience. This type of advertising is - as stressed in the introduction - cheaper and more credible than a classical one. Of course, after very few experiences with the same surprising product/service, surprise is not likely to appear any more (schema update) for the same customers but these customers will perhaps have convinced some others - through WOM - to purchase the product/service by that time. When using surprise as a marketing tool, companies should, however, adhere to clear ethical guidelines. As for the use of fear in advertising, surprise might be misused by companies only guided by their profitability. Moreover, surprising customers is not totally free of costs. Companies need to invest time in understanding their customers' schema and in creating surprising aspects in - or around - the product/service delivered. However, it does not need to be huge and expensive to be surprising, little things can work. Examples are: a little present (e.g. some chocolates, a birthday card, a ticket for a soccer match) offered on the client's birthday, something practical temporarily added to the product, lottery tickets offered one year after the first purchase in the shop. Adopting a 'surprise' strategy requires thus also a careful analysis of the costs and benefits (e.g. in terms of increased sales and reduced advertising costs) of such a strategy.

Further paths of research also arise from this pilot study. For example, potential moderating factors of the link between surprise and WOM, such as expertise, familiarity, age, sex, personality, involvement might be investigated. Moreover, a broader model of the influence 
of surprise on WOM - taking into account a larger variety of determinants of WOM such as expectations, disconfirmation, satisfaction, quality - might be built and empirically tested. A longitudinal qualitative study of WOM elicited by surprising experiences would also generate some new insights into the evolution of the content of WOM over time. Eventually, the influence of surprise might be researched in depth within some other areas of consumer behaviour such as advertising.

It should be borne in mind that the results of this pilot study do have some limitations. The relatively small size and convenient nature of the sample limit their generalisability. However, the purpose was more to shed light on some theoretical antecedents of WOM rather than to provide some general patterns of behaviour of a population. A more important limit is the use of a single type of measure - verbal report - for recording surprise or emotions more generally. None existing scale perfectly records and taps all aspects of emotion and a multi-method approach with both verbal and non-verbal measures is, therefore, recommended in order to assess the polarity, intensity and quality of emotions (Derbaix and Poncin, 1999). Even though the marketing literature has traditionally favoured verbal reports, these reports suffer from a number of drawbacks (e.g. respondents tend to rationalise their emotions, cannot always identify their emotional state or may not want to share their emotions with strangers; Derbaix and Poncin, 1999; Derbaix, 1995). Finally, even if all care has been taken to ease the respondents' recall (e.g. the most recent surprising episodes were prompted), retrospection bias might still have affected the answers.

To conclude, substantial interest in the role of affective reactions in consumer behaviour was sparked by influential studies in the eighties. The thrust of this literature was that the study of emotions is as important as the study of cognitions. In this respect, our research has shown the 
potential of influence of surprise within the framework of consumer behaviour. Even if the present investigation has obviously just scratched the surface of a fascinating iceberg we believe that our results can serve as a suggesting point of departure for future research.

\section{Acknowledgements}

The authors are indebted to Alexandre Martin for his invaluable assistance during data collection. 
Figure 1. The syndrome of surprise

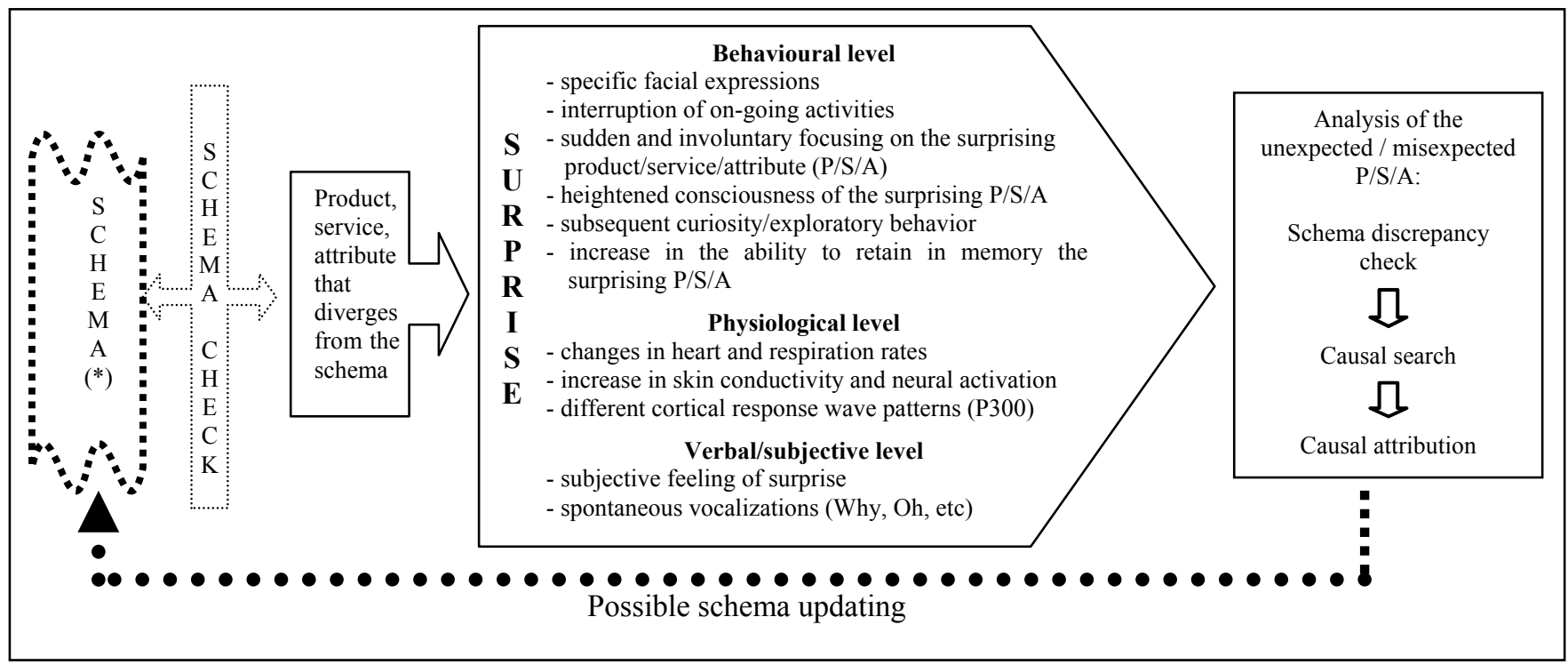

Source: Vanhamme (2000), Westburn Publishers $(C$ 
Figure 2. Mediation analysis

a. 'Positive sample' $(N=100)$

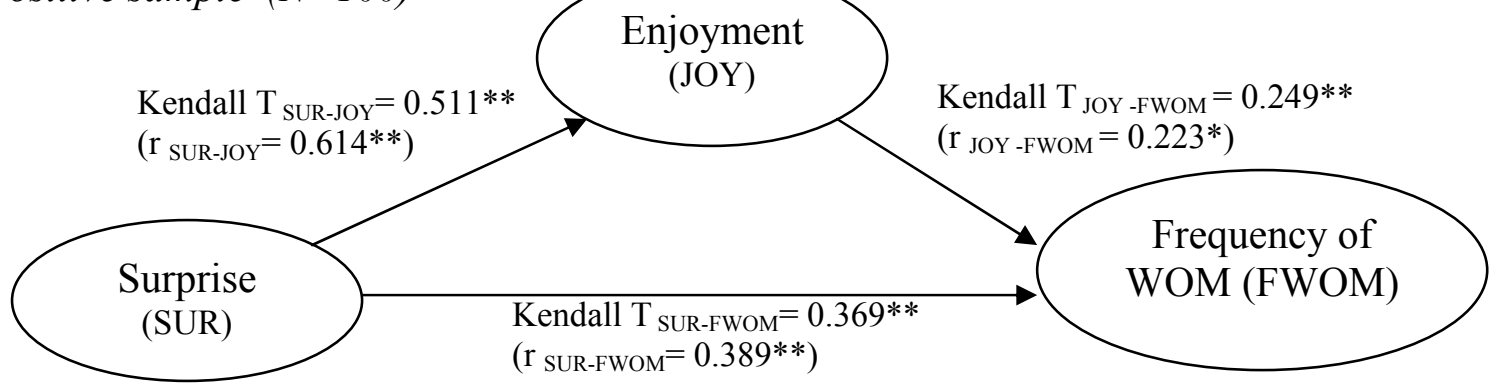

\begin{tabular}{|l|c|}
\hline Kendall T SUR FWOM . JOY & $0.29, \mathrm{p}_{1 \mathrm{~T}}=0.000^{* *}$ \\
\hline FWOM $=\mathrm{f}(\mathrm{SUR})$ & $\mathrm{p}_{1 \mathrm{~T} \mathrm{SUR}}=0.000^{* *}$ \\
\hline $\mathrm{JOY}=\mathrm{f}(\mathrm{SUR})$ & $\mathrm{p}_{1 \mathrm{~T} \mathrm{SUR}}=0.000^{* *}$ \\
\hline FWOM $=\mathrm{f}(\mathrm{SUR}, \mathrm{JOY})$ & $\mathrm{p}_{\mathrm{IT} \mathrm{SUR}}=0.000^{* *} ; \mathrm{p}_{1 \mathrm{~T} \text { JOY }}=0.416^{4}$ \\
\hline
\end{tabular}

b. 'Negative' sample $(N=100)$

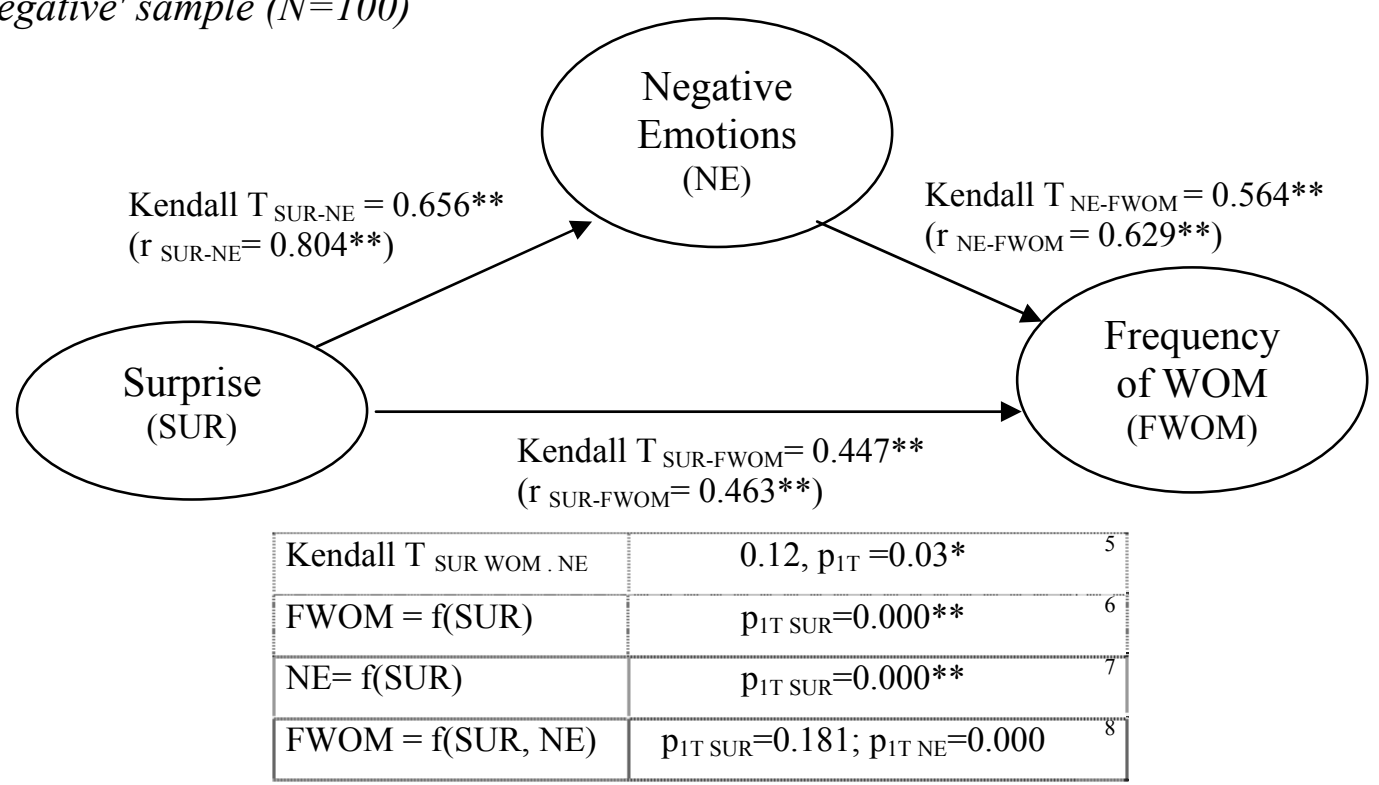

Note 1: Negative emotion (NE) is an aggregation of all items of negative emotions (i.e. items for anger, disgust, contempt, fear and distress, see appendix 2). All items loaded very highly on the first factor of the principal component analysis we carried out (between 0.74 and 0.89). The Cronbach alpha for NE is 0.97 . Kendall $\mathrm{T}$ [Pearson] correlations between surprise and each of the negative emotions (i.e. anger, disgust, contempt, fear and distress) are between 0.55 and 0.66 [between 0.60 and 0.82] and Kendall $\mathrm{T}$ [Pearson] correlations between those emotions and FWOM are between 0.46 and 0.59 [between 0.52 and 0.67 ].

Note 2: Cells 1 and 5 refer to the non parametric partial analysis, i.e. the Kendall partial rank-order correlation (Siegel and Castellan, 1988). For example, Kendall T suR Fwom . Joy amounts to 0.29 and is significantly larger than zero $(\mathrm{p}=0.000)$. This partial coefficient can be compared to the Kendall coefficient - reported in the upper part of the figure (0.369, first graph) - which does not partial out the influence of enjoyment. (See cells 2-4 and 6-8 referring to the parametrical Baron and Kenny (1986) procedure for mediation as additional information).

* and ** stand for $\mathrm{p}<0.05$ and $\mathrm{p}<0.01$ respectively (1-tail tests). 


\section{Appendix 1: Selected vignettes}

Case 1: Novelty of the product/service

Respondent 22: "It was a micro-fibre duster. Alone, I tried that new duster and I was surprised by its efficiency! It does not need any detergent. So I expected a duster but I was really surprised because I did not need to use any detergent and it really gave furniture a remarkable shine." $(+)$

Case 2: Price/quality ratio

Respondent 26: "I bought a medicine - to relieve allergies - in a pharmacy. I did not dare going to a pharmacy any more with less than 1000 Belgian francs in my purse. This was a medicine that only cost 42 Belgian francs! I thought I would have to pay some $300-400$ Belgian francs. So I was really surprised by the price I had to pay.” $(+)$

Case 3: The product/service is not the product/service ordered

Respondent 62: "I ordered a mechanical equipment in a mail order catalogue. The equipment that was delivered was not the one I ordered. When you order something from a catalogue, you hope that you will receive what you have ordered." (-) 
Case 4.:Out of stock problems

Respondent 84: "Purchase of a car - a BMW - from a BMW dealer. After I made the decision, I learnt that the waiting time was of 9 months!" (-)

Case 5: Bad(good) quality, poor (good) performance of the product/service

Respondent 96: "A can of foie gras - Isles de France - bought in Auchan in France. We were on the Belgian coast, in our little cottage, for an intimate dinner for two. We were about to "savour" our starter. A suspect smell, a grainy appearance, and a rancid taste. We did not have the same kind of problem previously with a similar purchase. So we did not think we would be so disappointed." (-)

Case 6: Factors related to atmospherics

Respondent 43: "We wanted to have dinner and were looking for a restaurant in Alsace (East of France). In the main street, we saw a little restaurant FOR NON SMOKERS ONLY. Besides this very nice aspect, food was delicious and the waiters were very convivial --- with the non smokers." $(+)$

Note: Text units have been translated from French by the authors.

Legend:

(-): 'negative' surprise

$(+)$ : 'positive' surprise 


\section{Appendix 2: scales}

\section{Items for surprise and subsequent affective reactions (5 points scale items):}

\begin{tabular}{|c|c|}
\hline DES items - French version (used in the study) & DES items - Original English version \\
\hline Surprise & Surprise \\
\hline Items: surpris(e), étonné(e), stupéfait(e) & Items: surprised, amazed, astonished \\
\hline Enjoyment & Enjoyment \\
\hline Items: amusé(e), joyeux(se), gai(e) & Items: joyful, delighted, happy \\
\hline Distress & Distress \\
\hline Items: triste, cafardeux(se), déprimé(e) & Items: sad, downhearted, discouraged \\
\hline Anger & Anger \\
\hline Items: en colère, irrité(e), révolté(e) & Items: angry, mad, enraged \\
\hline Fear & Fear \\
\hline Items: apeuré(e), effrayé(e), terrifié(e) & Items: afraid, scared, fearful \\
\hline Disgust & Disgust \\
\hline Items: dégouté(e), écoeuré(e), répugné(e) & $\begin{array}{l}\text { Items: disgusted, feeling of distaste, feeling of } \\
\text { revulsion }\end{array}$ \\
\hline Contempt & \\
\hline Items: dédaigneux(se), méprisant(e) & Contempt \\
\hline & Items: disdainful, contemptuous, scornful \\
\hline
\end{tabular}

\section{Measure of WOM :}

\section{Frequency}

In French : Après avoir vécu cette expérience [surprenante], en avez-vous parlé à quelqu'un ? $\square$ oui $\square$ non Si oui, combien de fois avez-vous parlé de votre expérience [surprenante], après que celle-ci s'est produite (au total, toutes personnes confondues)?

In English : After your [surprising] experience, did you talk about it with someone ? $\square$ yes $\quad \square$ no If yes, how often did you talk about your [surprising] experience after it occurred (in total, all people included)?

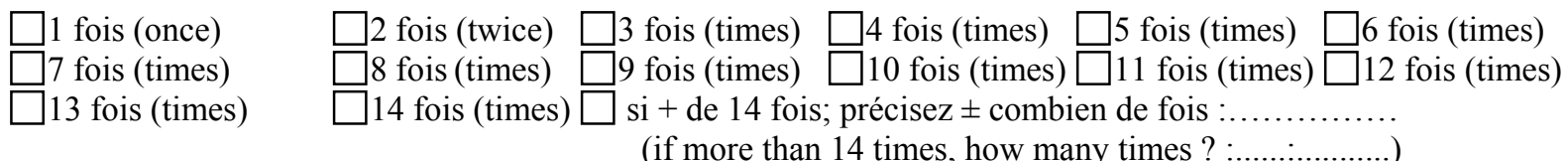

\section{Amount}

In French : Citez tous les éléments dont vous avez parlé ( toutes personnes confondues ) se rapportant à cette expérience [surprenante], après que celle-ci s'est produite.

In English : Cite all different elements you mentioned about this [surprising] experience (all people included), after it occurred.

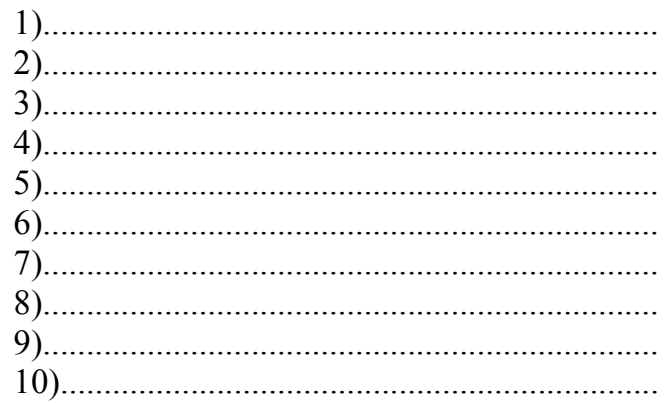




\section{References}

Adelman, M.B., \& Ahuvia, A.C. (1995). The antecedents, processes and outcomes of social support in an introductory service. Journal of Business Research, 32, 273-282.

Arndt, J. (1967a). Word-of-mouth Advertising: A review of the literature. New York: Advertising Research Foundation.

Arndt, J. (1967b). Role of product-related conversations in the diffusion of a new product. Journal of Marketing Research, 4 (August), 291-295.

Bain, A. (1874). The emotions and the will (3rd ed.). N-Y: Appleton.

Baron, R. M., \& Kenny, D. A. (1986). The moderator-mediator variable distinction in social psychological research: conceptual, strategic and statistical considerations. Journal of Personality and Social Psychology, 51 (6), 1173-82.

Bayus, B.L. (1985). Word-of-mouth: the indirect effects of marketing efforts. Journal of advertising research, 25 (June/July), 31-39.

Bitner, M.J., Booms, B.H., \& Stanfield Tetreault, M. (1990). The service encounter: diagnosing favorable and unfavorable incidents. Journal of Marketing, 54 (January), 71-84.

Buttle, F.A. (1997). I heard it through the grapevine: issues in referral marketing. Proceedings of the $5^{\text {th }}$ international colloquium in relationship marketing. Cranfield School of Management. Cranfield University, England.

Charlesworth, W.R. (1969). The role of surprise in cognitive development. In Elkind, D., \& Flavel, J.H., Studies in cognitive development, essays in honor of Jean Piaget (pp. 257-314). London: Oxford University Press.

Christophe, V., \& Rimé, B. (1997). Exposure to the social sharing of emotion: emotional impact, listener responses and secondary social sharing. European Journal of Social Psychology, 27, 37-54.

Derbaix, C., \& Pham, M. T. (1991). Affective reactions to consumption situations: a pilot investigation. Journal of Economic Psychology, 12 (2), 325-355.

Derbaix, C. (1995). The impact of affective reactions on attitudes toward the advertisement and the brand: A step toward ecological validity. Journal of Marketing Research, 4 (11), 470-479. 
Derbaix, C., \& Poncin, I. (1999). Process Tracing of Affective Reactions Elicited by Commercials : Assessing the Explanatory Power of the Outputs of the Feelings Monitor and the Coding of Facial Expressions. In B. Dubois, T. Lowrey, J.L. Shrum, M. Vanhuele, European Advances in Consumer Research, Vol. IV, 166-173.

Derbaix, C., \& Vanhamme, J. (2000). The 'you know what?' syndrome - how to use surprise for gaining success. In Wierenga, B., Smidts, A., \& Antonides, G. (eds.), Proceedings of the $29^{\text {th }}$ conference of the European Marketing Academy (CD-Rom). Rotterdam: Erasmus University Rotterdam.

Desai, M.M. (1939). Surprise: a historical and experimental study. In Drever, J., British Journal of Psychology, Monograph Supplements 22 (pp. 1-124). London: Cambridge University Press.

Ekman, P., \& Friesen, W. (1975). Unmasking the Face. New Jersey: Prentice-Hall, Englewood Cliffs.

Ekman, P., \& Friesen, W. (1985). Is the startle reaction an emotion? Journal of Personality and Social Psychology, 49 (5), 1416-1426.

Filser, M. (1996). Vers une consommation plus affective? Revue Française de Gestion, 110, 90-99.

Flanagan, J. C. (1954). La technique de l'incident critique. Revue de Psychologie Appliquée, 4, $165-$ 185 and $267-295$

Folkes, V.S. (1984). Consumer reactions to product failure: an attributional approach. Journal of Consumer Research, 10, 398-409.

Gendolla, G.H.E. (1997). Surprise in the context of Achievement: the role of outcome valence and importance. Motivation and Emotion, 21(2), 165-193.

Goleman, D. (1997). Emotional Intelligence: why it can matter more than IQ. Great Britain: Bloomsbury.

Hart, W.L., Heskett, J.L., \& Sasser, W.E. (1990). The profitable art of service recovery. Harvard Business Review, 68 (July-August), 148-156.

Hartline, M.D., \& Jones, K.C. (1996). Employee performance cues in a hotel service environment: influence on perceived service quality, value and word-of-mouth intentions. Journal of Business Research, 35, 207-215. 
Hausknecht, D.R. (1988). Emotional measures of satisfaction/dissatifaction. Journal of Consumer Satisfaction/dissatisfaction and Complaining Behavior, 1, 25-33.

Holmes, J.H., \& Lett, J.D. (1977). Product sampling and Word-of-mouth. Journal of Advertising Research, 17(5), 35-40.

Izard, C.E. (1977). Human Emotions. New York: Plenum Press.

Izard C.E., Buechler S. (1980). Aspects of consciousness and personality in terms of differential emotions theory. In Plutchik, P. \& Kellerman, Emotion: theory, research, and experience, vol 1. (pp. 165-187). New-York: Academic Press.

Izard, C.E. (1991). The Psychology of Emotions. New-York: Plenum Press.

Johnston, R. (1995). The determinants of service quality: satisfiers and dissatisfiers. International Journal of Service Industry Management, 6 (5), 53-71.

Katz, E., \& Lazarsfeld, P.F. (1964). Personal influence: The part played by people in the flow of mass communication. New York: The Free Press.

King, K.W., \& Tinkham, S.F. (1990). The learning and retention of outdoor advertising. Journal of Advertising Research, 29 (Dec./January), 47-51.

Maute, M.F., \& Dubé, L. (1999). Patterns of emotional responses and behavioral consequences of dissatisfaction. Applied Psychology, 48(3), 349-366.

Meyer, W-U., Niepel, M., Rudolph, U., \& Schützwöhl, A. (1991). An experimental analysis of surprise. Cognition and Emotion, 5(4), 295-311.

Meyer, W.-U., \& Niepel, M. (1994). Surprise. In Ramachandran, V. S., Encyclopedia of Human Behavior, Vol 3 (pp.353-358). California: Academic press.

Meyer, W.-U, Niepel, M., Rudolph, U., \& Schützwöhl, A. (1994). Überraschung und Attribution. In Försterling, F., \& Stiensmeier-Pelster, J., Attributionstheorie, (pp.105-121). Göttingen: Hofgrefe.

Meyer, W-U., Reisenzein, R., \& Schützwohl, A. (1997). Toward a Process Analysis of Emotions: The case of surprise. Motivation and Emotion, 21(3), 251-274.

Niepel, M., Rudolph,U., \& Schützwöhl, A. (1994). Temporal characteristics of the surprise reaction induced by schema discrepant visual and auditory events. Cognition and Emotion, 8 (5), 433-452. 
Oliver, R.L. (1997). Satisfaction: on a behavioral perspective on the consumer. New-York: McGrawHill.

Oliver, R.L., Rust, R. T., \& Varki, S. (1997). Customer delight: foundations, findings, and managerial insight. Journal of Retailing, 73 (3), 311-336.

Ortony, A., Clore, G.L., \& Collins (1988). The Cognitive Structure of Emotions. Cambridge: Cambridge University Press.

Plutchik, R. (1980). Emotion: a psychoevolutionary synthesis. New-York: Harper \& Row.

Reichheld, F. F., \& Sasser, W. E. Jr. (1990). Zero defections: quality comes to services. Harvard Business Review, 68 (5), 105-111.

Reisenzein, R., Meyer, W-U., \& Schützwohl, A. (1996). Reactions to surprising events: a paradigm for emotion research. In Frijda, N. H., Proceedings of the 9th Conference of the International Society for Research on Emotions (pp. 292-296). Toronto: ISRE.

Reisenzein, R. (2000). Exploring the strength of association between the components of emotion syndrome: the case of surprise. Cognition and Emotion, 14(1), 1-38.

Reisenzein, R., \& Bördgen, S. (1998). Evidence for strong dissociation between emotion and facial display: the case of surprise. Unpublished manuscript, University of Bielenfeld, Germany.

Ribot T.H. (1911). The psychology of emotions. London: W.C. Scott, ltd.

Richins, M.L. (1983). Negative word-of-mouth by dissatisfied consumers: a pilot study. Journal of Marketing, 47 (Winter), 68-78.

Richins, M.L. (1997). Measuring emotions in the consumption experience. Journal of Consumer Research, 24 (2), 127-146.

Rimé, B., Mesquita, B., Philippot, P., Boca, S. (1991a). Beyond the emotional event: six studies on the social sharing of emotions. Cognition et Emotion, 5(5-6), 436-466.

Rimé, B., Noël, M.P., Philippot, P. (1991b). Episode émotionnel, réminescences mentales, et réminescences sociales. Cahiers internationaux de Psychologie Sociale, 11, 93-104. 
Rimé, B., Philippot, P., Boca, S., Mesquita B. (1992). Long lasting cognitive and social consequences of emotion: social sharing and rumination. In Stroebe, W., \& Hewstone, M., European Review of Social Psychology 3, (pp.225-258). Chichester: Wiley.

Rimé, B., Philippot „P., Finkenhauer, C., Legast, S., Moorkens, P., \& Tornqvist, J. (1995). In Rimé B., Questions approfondies en psychologie expérimentale: Emotion et Expression. Unpublished text book. Belgium: Université Catholique de Louvain.

Rimé, B., Finkenhauer, C., Luminet, O., Zech, E., et Phillipot, P. (1998). Social sharing of Emotions: New Evidence and New Questions. In Stroebe, W., \& Hewstone, M., European Review of social psychology, 9, (pp.145-189). Chichester: Wiley.

Ruckmick, C.A. (1921). A preliminary study of the emotions. Psycholgical Monographs, 30, 30-35.

Rumelhart, D.E. (1984). Schemata and the cognitive system. In Wyer, R.S. Jr., \& Srull, T.K., Hanbook of social cognition 1 (pp.161-188). Hillsdale, NJ: Lawrence Erlbaum Associates Inc.

Rust, R .T., \& Oliver, R.L. (2000). Should we delight the customer ?. Journal of The Academy of Marketing Science, 28 (1), 86-94.

Saucier G. (1994). Mini-markers: a brief version of Goldberg's unipolar Big Five Markers. Journal of Personality Assessment, 63, 506-516.

Scherer, K.R. (1984). On the nature and function of emotion : a component process approach. In Scherer, K.R., \& Ekman, P., Approaches to emotion (pp293-317). Hillsdale, NJ: Lawrance Erlbaum Associates Inc.

Schützwohl, A. (1998). Surprise and Schema Strength. Journal of Experimental Psychology, Learning, Memory and Cognition, 24(5), 1182-1199.

Siegel, S., \& Castellan, N.J. (1988). Nonparametric statistics for the behavioral sciences. New-York: MacGraw Hill.

Singh, J. (1988). Consumer Complaint Intentions and Behavior: Definitional and Taxonomical Issues. Journal of Marketing, 52 (January), 93-107.

Söderlund, M. (1998). Customer satisfaction and its consequences on customer behaviour revisited: The impact of different levels of satisfaction on word-of-mouth, feedback to supplier and loyalty. International Journal of Service Industry Management, 9 (2), 169-188. 
Solomon, M. (1998). Consumer Behavior. New-Jersey: Prentice Hall.

Stiensmeier-Pelster, J., Martini, A., \& Reisenzein, R (1995). The role of surprise in the attribution process. Cognition and Emotion, 9(1), 5-31.

Swan, J.E., \& Combs, L.J. (1976). Product performance and consumer satisfaction: a new concept. Journal of Marketing, 40 (April), 25-33.

Swan, J.E., \& Oliver, R.L. (1989). Postpurchase communications by consumers. Journal of Retailing, 65 (Winter), 516-533.

Tanner J.F. Jr. (1996). Buyer perceptions of the purchase process and its effects on customer satisfaction. Industrial Marketing Management, 25, 125-133.

Taylor, S.E. (1991). Asymmetrical effects of positive and negative events: the mobilizationminimization hypothesis. Psychological Bulletin, 110(1), 67-85.

Tax, S.S., \& Chandrashekaran, M. (1992). Consumer decision making following a failed service encounter: a pilot study. Journal of Consumer Satisfaction, Dissatisfaction and Complaining Behavior, 5, 55-68.

Tax, S.S., Chandrashekaran, M., \& Christiansen, T. (1993). Word-of-Mouth in consumer decisionmaking: an agenda for research. Journal of Consumer Satisfaction, Dissatisfaction and Complaining Behavior, 6, 75-80.

Tomkins, S.S. (1962). Affect, Imagery, Consciousness: the positive affects, 1. New-York: Springer Publishing Co.

Vanhamme, J. (2000). The link between Surprise and Satisfaction: an exploratory research on how best to measure surprise. Journal of Marketing Management, 16 (6), 565-582.

Vanhamme, J., \& Lindgreen, A. (2001). Gotcha! Findings from an exploratory research on the dangers of using surprise in the mail order business. Psychology \& Marketing, 18 (7), forthcoming.

Warren, H.C. (1920). Human Psychology. Boston: Houghton Mifflin.

Webster, C. (1988). The importance consumers place on professional services. Journal of Services Marketing, 2 (1), 59-70. 
Webster, C. (1991). Influences upon consumer expectations of services. Journal of Services Marketing 5 (1) 5-17.

Westbrook, R.A. (1987). Product/Consumption-Based affective Responses and Postpurchase Process. Journal of Marketing Research, 24 (3), 258-270.

Westbrook, R.A., \& Oliver, R. L. (1991). The dimensionality of consumption emotion patterns and consumer satisfaction. Journal of Consumer Research, 18 (1), 84-91.

Woodworth, R.W., \& Schlosberg, H. (1954). Experimental psychology. New-York: Holt.

Wilkie, W.L. (1990). Consumer Behavior. New York: John Wiley \& Sons.

Weiner, B. (1985). An attributional theory of achievement motivation and emotion. Psychological Review, 92, 548-573.

Zillmann, D. (1983). Transfer of excitation in emotion behavior. In Cacioppo, J.T., \& Petty, R.E, Social Psychophysiology (pp.215-240). New-York: Guilford. 